\title{
BMJ Open Measuring patient safety culture in maternal and child health institutions in China: a qualitative study
}

\author{
Yuanyuan Wang, ${ }^{1,2}$ Weiwei Liu, ${ }^{2}$ Huifeng Shi, ${ }^{1}$ Chaojie Liu, ${ }^{3}$ Yan Wang ${ }^{1}$
}

To cite: Wang Y, Liu W, Shi H, et al. Measuring patient safety culture in maternal and child health institutions in China: a qualitative study. BMJ Open 2017;7:e015458. doi:10.1136/ bmjopen-2016-015458

- YW and CL contributed equally.

- Prepublication history and additional material are available. To view these files please visit the journal online (http://dx.doi org/10.1136/bmjopen-2016015458).

Received 6 December 2016 Revised 22 May 2017 Accepted 30 May 2017

\section{(a) CrossMark}

${ }^{1}$ Department of Maternal and Child Health, School of Public Health, Peking University, Beijing, China

${ }^{2}$ Second Outpatient Department, Peking University Third Hospital, Beijing, China

${ }^{3}$ School of Psychology and Public Health, La Trobe University, Melbourne, Australia

\section{Correspondence to}

Professor Yan Wang; wangyan@ bjmu.edu.cn and Professor Chaojie Liu; c.liu@latrobe. edu.au

\begin{abstract}
Introduction Patient safety culture (PSC) plays a critical role in ensuring safe and quality care. Extensive PSC studies have been undertaken in hospitals. However, little is known about PSC in maternal and child health (MCH) institutions in China, which provide both population-based preventive services as well as individual care for patients. Objectives This study aimed to develop a theoretical framework for conceptualising PSC in MCH institutions in China.
\end{abstract}

Methods The study was undertaken in six $\mathrm{MCH}$ institutions (three in Hebei and three in Beijing). Participants $(n=118)$ were recruited through stratified purposive sampling: 20 managers/administrators, 59 care providers and 39 patients. In-depth interviews were conducted with the participants. The interview data were coded using both inductive (based on the existing PSC theory developed by the Agency for Healthcare Research and Quality) and deductive (open coding arising from data) approaches. A PSC framework was formulated through axial coding that connected initial codes and selective coding that extracted a small number of themes.

Results The interviewees considered patient safety in relation to six aspects: safety and security in public spaces, safety of medical services, privacy and information security, financial security, psychological safety and gap in services. A 12-dimensional PSC framework was developed, containing 69 items. While the existing PSC theory was confirmed by this study, some new themes emerged from the data. Patients expressed particular concerns about psychological safety and financial security. Defensive medical practices emerged as a PSC dimension that is associated with not only medical safety but also financial security and psychological safety. Patient engagement was also valued by the interviewees, especially the patients, as part of PSC.

Conclusions Although there are some common features in PSC across different healthcare delivery systems, PSC can also be context specific. In MCH settings in China, the meaning of 'patient safety' goes beyond the traditional definition of patients. General well-being, health and disease prevention are important anchor points for defining PSC in such settings.

\section{INTRODUCTION}

Patient safety has become a global concern over the last two decades. It is agreed that patient safety culture (PSC), which is defined
Strengths and limitations of this study

- The study explored the concept of patient safety and patient safety culture (PSC) from the points of view of managers/administrators, care providers and patients.

- The study was conducted in maternal and child health institutions, which provided population-based preventive services as well as individual care for patients.

- The results are context specific, and caution should be taken when generalising the results.

- The study provides a high-level classification of patient safety, which should not be treated as an operational taxonomy to be used directly in practices.

as the 'shared values, beliefs, norms and procedures related to patient safety among members of the organisation', ${ }^{1}$ is fundamental for safe and quality care. ${ }^{2-6}$ In the literature, there are several distinct but related terms describing PSC, such as patient safety climate and patient safety attitudes. Culture is something that can be passed on and is relatively enduring. ${ }^{7}$ It is reflected in normalised behaviours and practices. Climate, on the other hand, provides a snapshot of the overwhelming perceptions of people in regard to PSC. ${ }^{89}$ Attitudes refer to how people see and respond to matters associated with patient safety. ${ }^{10}$ All of the three concepts are associated with safe behaviours, processes and outcomes. $^{5}$ 11-13 The commonly accepted PSC elements cover a wide range of domains, including, but not limited to, leadership, communication, teamwork, error reporting, continuous learning, evidence-based practice and non-punitive environment. ${ }^{1415}$

Maternal and child health $(\mathrm{MCH})$ is a priority on the global development agenda, such as the sustainable development goals (SDGs) promoted by the United Nations. ${ }^{16}$ China has achieved extraordinary success in $\mathrm{MCH}$ over the past few decades, thanks to the universal coverage of MCH care delivered by 
MCH institutions. ${ }^{1718}$ From 1990 to 2015 , the maternal mortality ratio (maternal deaths per 100000 live births) in China decreased from 114.2 to $17.7,{ }^{19}$ and under-five mortality rate (deaths per 1000 live births) dropped from 55.9 to $12.3 .^{20}$ There are $3071 \mathrm{MCH}$ institutions in China, covering all counties and cities. ${ }^{21}$ They are dedicated to providing four categories of MCH services: (1) maternal and obstetrical care such as premarital examinations; progestational consultations; and pregnancy, labour and postpartum services; (2) paediatric care including management of neonatal, infant and child growth and development; nutrition; and mental health, as well as the diagnosis and treatment of childhood diseases; (3) women's health, ranging from adolescent health and reproduction to nutrition, mental health, breast care, menopause and aged care; gynaecological services are also provided; (4) family planning services, such as health education, preconception counselling, contraception and reproductive healthcare services. The MCH institutions operate at provincial, municipal and county levels, forming a tiered comprehensive network. $^{22}$ A considerable number of policies and regulations have been devoted to strengthening the infrastructure, technologies and procedures of $\mathrm{MCH}$ services. $^{171823}$

Measuring PSC is important to help health workers to increase awareness and develop a better understanding of patient safety. It can also provide information support to managers to improve their managerial practices. Several PSC measurement tools have been developed. Of those tools, the Hospital Survey on Patient Safety Culture developed by the Agency for Healthcare Research and Quality, ${ }^{24}$ the Patient Safety Climate in Healthcare Organisations ${ }^{25}$ and the Safety Attitudes Questionnaire ${ }^{10}$ are most commonly used. They have been applied to a wide range of health institutions in various countries, ${ }^{26-28}$ including in China. ${ }^{29-33}$ However, the Chinese versions of these instruments followed a stringent translation protocol and considered little, if any, of the special contexts of Chinese health institutions.

This study aimed to explore the concept of patient safety and PSC in China's MCH institutions. Internationally, there is a dearth of literature that examines PSC in $\mathrm{MCH}$ institutions. Due to the unique features of $\mathrm{MCH}$ services, PSC components that need to be addressed in $\mathrm{MCH}$ institutions could be different from those in general hospitals. ${ }^{17} 34$ Since culture has the nature of profundity and abstruseness, ${ }^{35}$ it is essential to unveil its presentations and implications under specific contexts. The principles of qualitative research, in particular, the grounded theory, fit well with the objectives of this study. It allows us to generate a new (or modified) PSC framework without necessarily being restricted to any existing theoretical framework. ${ }^{36}{ }^{37}$ Instead of presenting details of PSC, this study intended to provide a high-level classification of patient safety and PSC for the MCH institutions in China.
METHODS

\section{Design}

This is a qualitative study conducted by a multidisciplinary research team, comprising experts in MCH (YYW (female), YW (female) and HS (male)), research methodology (CL (male)) and health services management (CL (male) and WL (female)). In-depth interviews were undertaken with health workers (managers/administrators and care providers) and patients to examine their perceptions and experiences of patient safety and PSC.

\section{Setting and sample}

Data were collected between November 2014 and April 2015 in six MCH institutions: three in Hebei and three in Beijing. These institutions were purposively selected, considering diversities in staffing, resources (eg, beds), and scope and volume of services (eg, outpatient, inpatient and birth delivery). The number of beds in the participating MCH institutions ranged from 40 (at the county level) to 460 (a large metropolitan centre). Further details of the participating $\mathrm{MCH}$ institutions can be found in the online supplementary appendix table 1.

A stratified purposive sampling strategy was adopted to recruit participants. In each $\mathrm{MCH}$ institution, the potential participants were divided into four to five groups: management/administration (eg, general office, medical administration, nursing administration, infection control), MCH clinics (eg, paediatrics, gynaecology, obstetrics), population health services (eg, child healthcare, women's healthcare, preventive care), allied health services (eg, pharmacy, imaging, laboratory) and other clinical services (eg, internal medicine, surgery, dental, traditional Chinese medicine). In each institution, between 2 and 5 managers/administrators, 7 and 12 care providers (including doctors, nurses, public health workers, midwives, and allied health professionals) and 5 and 8 patients (including caregivers of children) were invited to participate in the study. Three invited interviewees (one doctor and two patients) withdrew due to disruption caused by other urgent matters. The final sample size was determined by the saturation of information when no new theme emerged from the coding. The saturation of information was deemed to be achieved when the entire research team (especially those who performed the interviews and coding) reached consensus. This resulted in a final sample size of 118, including 20 managers/administrators $(16.9 \%), 59$ care providers $(50.0 \%)$ and 39 patients $(33.1 \%)$. The characteristics of participants are presented in the online supplementary appendix tables 2 and 3 .

\section{Data collection, processing and analyses}

This study used both inductive and deductive approaches in data collection, coding and analyses. While the inductive approach tested the fitness of data into the existing PSC theories, the deductive approach guided by the grounded theory allowed the researchers to keep mind open and generate new theories through the data. ${ }^{36}$ 
The interview guides were developed based on a pretested tool in a previous study. ${ }^{38}$ However, the interviewers were trained to respond to the interviewees in a flexible way in order to obtain in-depth information. They were encouraged to ask questions that were not listed in the interview guides. At the end of each interview session, the interviewers reviewed the interview guides to ensure that the interview had covered all the questions listed in the guides. No repeated interviews were undertaken.

All interviews were conducted face to face in the $\mathrm{MCH}$ institutions, led by two chief investigators (YYW (female) and HS (male)) and assisted by three trained interviewers (with a master or PhD degree). Prior to each interview session, the interviewers introduced themselves and the purpose, contents, ethical principles and declarations of the study and obtained written informed consent from the participants. Each interview lasted $15-50 \mathrm{~min}$ and was audio recorded. The interviewers also took notes on the environment of the interview, the body language of respondents, self-reflection and any other information they thought necessary.

Data analyses took place concurrently with data collection. Interview strategies (including the questions asked) were adjusted in subsequent interviews. The research team met regularly, discussing the findings and determining whether additional samples were needed.

All audio records were transcribed verbatim. We used NVivo 8.0 software to perform coding and analyses on the transcribed data and interview notes. The coding procedure followed the principles of grounded theory. ${ }^{36}$ We started with open coding, which generated numerous codes from the raw data reflecting the panorama of the data. Original words were extracted to label the codes whenever it was possible. The second step involved axial coding. The initial codes were compared and condensed, with similar codes being merged using a new label that could describe all of the merged initial codes. The connections between different codes were identified by referring back to the raw data. This reduced the number of codes significantly. The third step was selective coding, which further abstracted key themes from the scattered codes. The selective coding considered the fitness of the condensed codes into the existing PSC theoretical framework developed by the Agency for Healthcare Research and Quality. Additional themes were established for those codes that did not fit well into the existing framework. Finally, we translated the codes into 'dimensions' (high-level framework) and 'items' embedded in each dimension (see online supplementary appendix table 4).

\section{Reliability and validity of coding}

All data were coded in parallel by two researchers (YYW (female) and HS (male)). This ensured the validity of coding. ${ }^{3940}$ First, both researchers developed their own initial codes from the data. They then shared and discussed their coding and agreed on an operational list of codes. The agreed operational list of codes was eventually used for coding all of the data by the two researchers independently. Finally, another round of coding discussion was held, with modifications being made to the operational codes and the coding of all of the data into the final list of codes. The coding process is illustrated in the online supplementary appendix figure 1 .

The reliability of coding was tested through repeated coding. ${ }^{41}{ }^{42}$ About $10 \% \quad(n=12)$ of interview records were randomly selected for repeated coding: two from managers/administrators, six from care providers and four from patients. Two researchers recoded the data independently into the agreed operational list of codes. About $63.3 \%-100 \%$ of the codes were consistent between the two researchers. The two researchers then discussed and reached a consensus on the final coding, which was compared with the coding done in the full data analyses. The percentage of agreement (number of codes agreed on/total number of codes $\times 100 \%$ for each interview record) in repeated coding ranged from $62.2 \%$ to $82.5 \%$ (see online supplementary appendix table 5).

We did not seek feedback from the interviewees on the transcripts and coding due to a lack of contact details.

\section{RESULTS}

\section{What is patient safety?}

In the MCH setting, the concept of patient safety was linked to unwanted health outcomes, not necessarily adverse events as a result of medical interventions. The interviewees were concerned about both adverse events and the shortage of good outcomes.

Patient safety was categorised into six aspects (table 1): safety and security of public spaces (eg, falls, fire, property loss and damage), safety of medical services (through the entire process), privacy and information security, financial security, psychological safety and gap in services. Managers and care providers were more likely to highlight the safety of medical services $(65.0 \%$ and $52.5 \%$, respectively) and the safety and security of public spaces (55.0\% and $35.6 \%$, respectively) as a major concern in patient safety. By contrast, patients (53.8\%) wanted more on assurance of safety or avoided events (psychological safety). They (38.5\%) also believed that unnecessary interventions could lower their financial security, jeopardising their ability to pay for necessary interventions. While excessive interventions might be associated with adverse events, a lack of necessary interventions might be associated with negative consequences that could otherwise be avoided. Concerns about privacy and information security were shared by both health workers and patients, although a small percentage $(25.0 \%$ by managers/administrators, $5.1 \%$ by care providers and $2.6 \%$ by patients).

Illness is a painful and stressful experience... I hope doctors or nurses alleviate my anxieties and doubts with their professional answers and psychological support. (Patient)

I often encounter patients suffering from postnatal depression, with all kinds of worries and fears... It may 
Table 1 Number (percentage) of codes associated with patient safety in maternal and child health institutions

\begin{tabular}{|c|c|c|c|c|c|}
\hline \multirow[b]{2}{*}{ Code } & \multirow[b]{2}{*}{ Description } & \multicolumn{2}{|c|}{ Health workers ( $n 1=79)$} & \multirow[b]{2}{*}{$\begin{array}{l}\text { Patients } \\
\text { (n4=39) }\end{array}$} & \multirow[b]{2}{*}{$\begin{array}{l}\text { Total } \\
(n=118)\end{array}$} \\
\hline & & $\begin{array}{l}\text { Managers } \\
\text { (n2=20) }\end{array}$ & $\begin{array}{l}\text { Care providers } \\
\text { (n3=59) }\end{array}$ & & \\
\hline $\begin{array}{l}\text { 1. Safety and } \\
\text { security of public } \\
\text { spaces }\end{array}$ & $\begin{array}{l}\text { Incidents that happen in public spaces, } \\
\text { for example, falls, fires, property loss } \\
\text { and damage }\end{array}$ & $11(55.0 \%)$ & $21(35.6 \%)$ & $5(12.8 \%)$ & $37(31.4 \%)$ \\
\hline $\begin{array}{l}\text { 2. Safety of medical } \\
\text { services }\end{array}$ & $\begin{array}{l}\text { Errors in diagnostic and treatment } \\
\text { procedures; unintended outcomes }\end{array}$ & $13(65.0 \%)$ & 31 (52.5\%) & $9(23.1 \%)$ & $53(44.9 \%)$ \\
\hline $\begin{array}{l}\text { 3. Privacy and } \\
\text { information security }\end{array}$ & $\begin{array}{l}\text { Violation of privacy and disclosure of } \\
\text { information }\end{array}$ & $5(25.0 \%)$ & $3(5.1 \%)$ & $1(2.6 \%)$ & $9(7.6 \%)$ \\
\hline 4. Financial security & $\begin{array}{l}\text { Financial waste in unnecessary } \\
\text { interventions and a lack of ability to } \\
\text { pay for necessary interventions }\end{array}$ & $6(30.0 \%)$ & $6(10.2 \%)$ & 15 (38.5\%) & 27 (22.9\%) \\
\hline $\begin{array}{l}\text { 5. Psychological } \\
\text { safety }\end{array}$ & $\begin{array}{l}\text { Worry or anxiety associated with } \\
\text { unknown events }\end{array}$ & $5(25.0 \%)$ & $10(16.9 \%)$ & 21 (53.8\%) & $36(30.5 \%)$ \\
\hline 6. Gap in services & Gap between expectations and reality & $6(30.0 \%)$ & $12(20.3 \%)$ & $6(15.4 \%)$ & $24(20.3 \%)$ \\
\hline
\end{tabular}

be more effective to comfort them psychologically, even offering a hug or slightly tough love, to make patients feel better rather than to prescribe drugs. (Provider)

Some doctors like to prescribe lots of pills, infusions and examinations, whether or not they should, just to make a profit. (Patient)

Take this laboratory report (in his hand) as an example. I would not feel safe if I did not listen to the doctor's advice to take such a test. My doctors read it and then told me, "it is okay, and there is nothing to be worried about'. I felt safe at once, no matter whether it was necessary to do it or how much money I paid. (Patient)

\section{Patient safety culture}

Corresponding to the conceptualisation of patient safety, 12 dimensions (containing 69 items) emerged as key components of PSC (table 2): management support (six items), regulations and procedures (six items), staffing (three items), teamwork (five items), non-punitive response to adverse events (six items), openness in communication (eight items), risk awareness (six items), continuous learning (six items), self-efficacy (five items), defensive medical practices (four items), patient engagement (six items) and competing interest between public health and clinical services (eight items). Details on the PSC dimensions and items can be found in the online supplementary appendix table 4 .

Different views were found between health workers and patients. The top 5 most frequently coded dimensions from the data were self-efficacy $(100.0 \%)$, management support $(95.0 \%)$, regulations and procedures $(95.0 \%)$, continuous learning $(95.0 \%)$ and non-punitive response to adverse events $(85.0 \%)$ for managers; continuous learning $(93.2 \%)$, self-efficacy $(91.5 \%)$, regulations and procedures $(91.5 \%)$, management support $(89.8 \%)$ and staffing $(88.1 \%)$ for care providers; and self-efficacy $(94.9 \%)$, patient engagement $(87.2 \%)$, continuous learning (51.3\%), management support (43.6\%) and staffing $(41.0 \%)$ for patients. It was common to blame individuals for medical errors across all three groups of interviewees.

We have summarised the common causes of medical incidents, including poor communication, lack of knowledge and skills, not obeying guidelines and procedures, and so on. All of these causes are individual responsibilities. Punishment of departments or individuals, although sometimes attracts complains, is helpful for reducing the number of incidents and making rules and regulations work. (Manager)

A person who makes mistakes often is incompetent and should be fired. (Manager)

Punishment of individuals is fair to others who do not make mistakes. (Provider)

Medical errors and incidents are associated with personal attitudes and skills. (Patient)

The 12-dimensional framework for PSC confirmed the existing theoretical framework developed by the Agency for Healthcare Research and Quality. However, some new themes emerged.

Patients demanded more involvement in decision-making, whether it was in relation to planning and prevention or medical procedures. They advocated for patient rights. This component of PSC was supposed to address the 'gap between expectations and reality'. It also reflected the nature of $\mathrm{MCH}$, a kind of service comprising both preventive and clinical care.

Now young parents are well educated and usually learn relevant information on the Internet before seeking care for their babies; they would like more detailed and accurate explanations than before. (Provider) 
Table 2 Number (percentage) of codes associated with the 12 dimensions of patient safety culture in maternal and child health institutions

\begin{tabular}{|c|c|c|c|c|c|}
\hline \multirow[b]{2}{*}{ Dimension } & \multirow[b]{2}{*}{ Description of dimension } & \multicolumn{2}{|c|}{ Health workers $(\mathrm{n} 1=79)$} & \multirow[b]{2}{*}{$\begin{array}{l}\text { Patients } \\
\text { (n4=39) }\end{array}$} & \multirow[b]{2}{*}{$\begin{array}{l}\text { Total } \\
(n=118)\end{array}$} \\
\hline & & $\begin{array}{l}\text { Managers } \\
\text { (n2=20) }\end{array}$ & $\begin{array}{l}\text { Care providers } \\
\text { (n3=59) }\end{array}$ & & \\
\hline $\begin{array}{l}\text { 1. Management } \\
\text { support }\end{array}$ & $\begin{array}{l}\text { Prioritise patient safety; good } \\
\text { management practices }\end{array}$ & $19(95.0 \%)$ & $53(89.8 \%)$ & $17(43.6 \%)$ & $89(75.4 \%)$ \\
\hline $\begin{array}{l}\text { 2. Regulations and } \\
\text { procedures }\end{array}$ & $\begin{array}{l}\text { Rational and adjustable regulations and } \\
\text { policies, empowering health workers }\end{array}$ & $19(95.0 \%)$ & $54(91.5 \%)$ & $13(33.3 \%)$ & $86(72.9 \%)$ \\
\hline 3. Staffing & Staffing and workloads & $16(80.0 \%)$ & $52(88.1 \%)$ & $16(41.0 \%)$ & $84(71.2 \%)$ \\
\hline 4. Teamwork & $\begin{array}{l}\text { Teamwork within departments, across } \\
\text { departments and across institutions }\end{array}$ & $13(65.0 \%)$ & $47(79.7 \%)$ & $5(12.8 \%)$ & $65(55.1 \%)$ \\
\hline $\begin{array}{l}\text { 5. Non-punitive } \\
\text { response to } \\
\text { adverse events }\end{array}$ & $\begin{array}{l}\text { Non-punitive response to adverse } \\
\text { events based on root cause analyses; } \\
\text { feedback and learning }\end{array}$ & $17(85.0 \%)$ & $42(71.2 \%)$ & $6(15.4 \%)$ & $65(55.1 \%)$ \\
\hline $\begin{array}{l}\text { 6. Openness in } \\
\text { communication }\end{array}$ & $\begin{array}{l}\text { Adverse event reporting; open } \\
\text { communication with colleagues and } \\
\text { patients }\end{array}$ & $10(50.0 \%)$ & $38(64.4 \%)$ & $0(0.0 \%)$ & $48(40.7 \%)$ \\
\hline 7. Risk awareness & $\begin{array}{l}\text { Attitudes toward and awareness of } \\
\text { medical risks, errors and potential flaws }\end{array}$ & $15(75.0 \%)$ & $44(74.6 \%)$ & $13(33.3 \%)$ & $72(61.0 \%)$ \\
\hline $\begin{array}{l}\text { 8. Continuous } \\
\text { learning }\end{array}$ & $\begin{array}{l}\text { Continuous learning and training, not } \\
\text { limited to knowledge and skills }\end{array}$ & $19(95.0 \%)$ & $55(93.2 \%)$ & $20(51.3 \%)$ & $94(79.7 \%)$ \\
\hline 9. Self-efficacy & $\begin{array}{l}\text { Individual belief in one's ability to } \\
\text { succeed in tasks }\end{array}$ & $20(100.0 \%)$ & $54(91.5 \%)$ & 37 (94.9\%) & $111(94.1 \%)$ \\
\hline $\begin{array}{l}\text { 10. Defensive } \\
\text { medical practices }\end{array}$ & $\begin{array}{l}\text { Procedures serving for the purpose of } \\
\text { self-defense in disputes }\end{array}$ & $9(45.0 \%)$ & $22(37.3 \%)$ & $9(23.1 \%)$ & $40(33.9 \%)$ \\
\hline $\begin{array}{l}\text { 11. Patient } \\
\text { engagement }\end{array}$ & Patient involvements in decision-making & $15(75.0 \%)$ & $44(74.6 \%)$ & $34(87.2 \%)$ & $93(78.8 \%)$ \\
\hline $\begin{array}{l}\text { 12. Competing } \\
\text { interest between } \\
\text { public health and } \\
\text { clinical services }\end{array}$ & $\begin{array}{l}\text { Priority setting and resource allocation } \\
\text { between public health and clinical } \\
\text { services }\end{array}$ & $6(30.0 \%)$ & $6(10.2 \%)$ & 0 (0.0\%) & 12 (10.2\%) \\
\hline
\end{tabular}

Communication is very important. No matter what the conditions or risks, patients must be completely informed. (Patient)

Defensive medical practices emerged as another important component of PSC. Defensive practices could be presented in multiple ways, for example, rejection of a patient with high risks (risk aversion), compromised clinical decision in response to irrational requests from patients and unnecessary interventions to show 'obligations' that could favour health workers in disputes. Such practices eroded the trust between health providers and patients and would eventually bring harm to patients.

If a pregnant woman refuses to take a prenatal blood test, we suggest that our doctors write it down in her medical records, which would provide evidence in a dispute over a case of anemia. (Manager)

I refer premature infants to higher level hospitals as much as possible to prevent unexpected complications I cannot afford. (Provider)

Doctors rely on machines too much because they don't want to take any risks. (Patient)
There was competing interest between public health and clinical services in MCH institutions. Some health workers believed that managers might make clinical services a priority in the institution due to financial pressures. This was likely to divert much needed resources from public health services to clinical care, increasing the possibility of the occurrence of avoidable events.

\section{External factors associated with PSC}

PSC can be shaped by some external factors. In this study, the interviewees identified policy and social environments, poor health literacy of consumers and a lack of trust between patients and health workers as major factors influencing PSC in MCH institutions.

MHC institutions are subject to strict policy and regulatory rules. Some unintended consequences had arisen from this strong control. For example, staffing and personnel policies led to a shortage of staff and heavy workloads of health workers; insufficient government financial support limited the further development of $\mathrm{MCH}$ institutions, resulting in the profit-seeking behaviours of these institutions; $\mathrm{MCH}$ institutions at the 
county level had restricted access to a limited range of medicines. These policy arrangements had the potential to jeopardise patient safety and PSC.

For social stability purposes, hospitals are always compelled to compensate medical dispute profiteers, regardless of who is wrong. (Manager)

The government usually emphasizes the importance of public health in words but not in actions. Because of a lack of funds, public health tasks are always done as little as possible in fact. (Manager)

Since the institutional reforms in our region, countylevel MCH institutions are not allowed to supply some drugs and services anymore, which is a broadbrush approach that does not consider specific circumstances. (Provider)

The public media played a significant role in shaping the opinions of consumers. The large amount of unverified or exaggerated reports about medical incidents were blamed by the interviewees for causing distrust and conflicts between patients and health providers, fuelling the defensive practices of health workers.

Our medical staff is overloaded and the medical industry is at high risk. However, patients cannot understand these things, and medical accidents are reported by the mass media in a way that is always misleading and misinterpreted. (Manager)

Medical disputes probably happen in all hospitals. Doubts about the whole industry have spread into society. Additionally, a small thing can be magnified by the media and aggravate distrust. (Provider)

Healthcare is a coproduction process in which patients play a critical role. Poor health literacy limited the ability of patients to engage in patient safety management. The interviewees reported that some patients felt ashamed of their illness (especially female patients), some treated healthcare as a simple financial transaction of services, some doubted the intention of medical decisions, some held unreasonable expectations of medicines and had a low appreciation of preventive care, some simply disengaged and some misunderstood medical advice and failed to cooperate with health workers. There was a low level of recognition of the inherent inevitability of making mistakes by human beings.

People don't respect us. For example, some nurses have been physically attacked by parents for failing to insert the scalp needle on the first try. (Manager)

Some patients consider treating human bodies to be like repairing machines. You must ensure that they get better or they will make trouble for you. (Provider)

I couldn't understand the doctors perfectly, and I had to do what they told me. (Patient)

The lack of trust led patients to believe that they had to choose health workers in order to ensure safety. Accreditation, environments and the popularity of health facilities, and the professional title and qualifications of health workers could all serve for the purpose of provider selection. This information either came from their previous experiences or from sharing with others. Unfortunately, patients with a low income had to take into consideration the costs, compromising their choice of providers. The medical-seeking behaviours (figure 1) of patients had a great influence on PSC. In some cases, patients might challenge doctors using a second opinion obtained from other providers, peers or even the internet.

Some patients did not trust us. They would see several doctors for verification. (Provider)

I choose this hospital because it is big hospital with a good environment and many people come here seeking MCH services. (Patient)

I trust my doctor because one of my friends is acquainted with him. (Patient)

Before making the decision to give birth here, we read nearly all the comments about this hospital on the internet. (Patient)

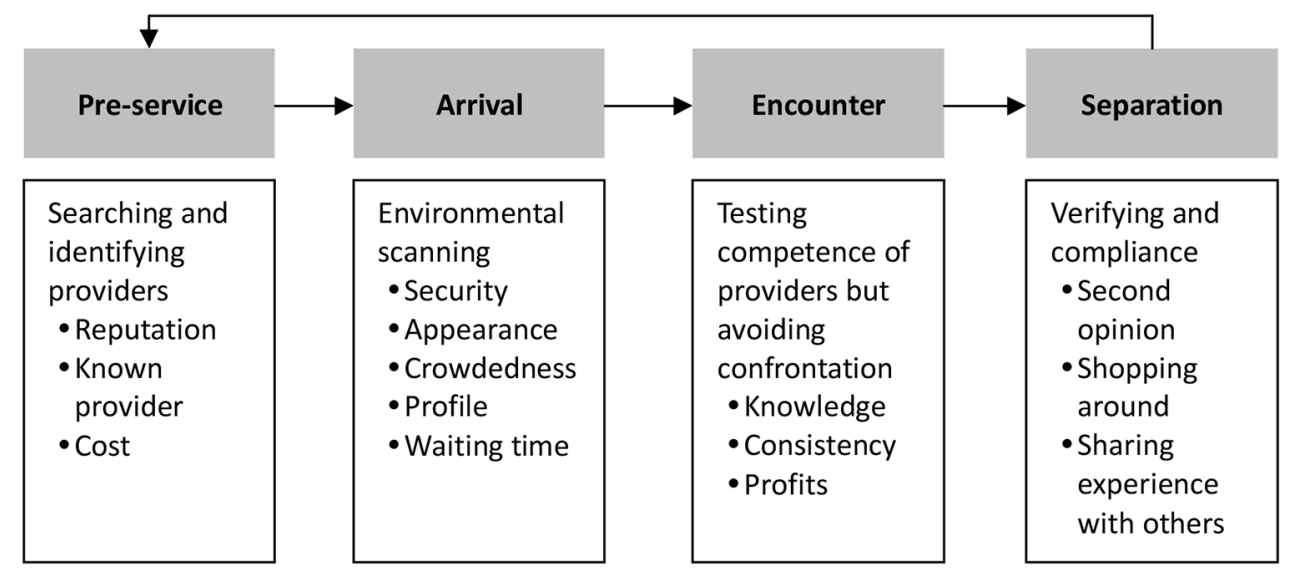

Figure 1 How patients make decisions when seeking health services. 


\section{DISCUSSION}

\section{An expanded definition of patient safety}

In the context of MCH institutions in China, the concept of patient safety goes beyond the scope of the definition provided by the WHO: 'the reduction of risk of unnecessary harm (impairment of structure or function of the body and/or any deleterious effect arising there from) associated with health care to an acceptable minimum'. ${ }^{43}$ Patient safety is no longer limited to service-associated adverse events. The absence or shortage of the wanted services became a safety concern because it can also lead to potential harm to patients. Patients often seek services from MCH institutions for the assurance of safety. Studies show that psychological safety assurance is to some extent related to distrustful relationships between patients and providers and inadequate informed consent. $^{445}$

Patient safety problems are not necessarily a result of medical errors. In this study, our interviewees expressed concerns about the environmental impacts on patient safety, such as the safety and security of public spaces. In resource-poor countries where consumers have to pay a large proportion of medical expenses out of pocket, patient safety can be jeopardised by a lack of financial security. Spending on unnecessary interventions may result in direct harm and prevent patients from receiving much needed interventions. ${ }^{46}{ }^{47}$ Some other studies also expanded the definition of patient safety, although from quite a different angle. ${ }^{48-50}$

\section{Special characteristics of PSC in MCH institutions}

$\mathrm{MCH}$ institutions possess some unique characteristics which differentiate them from general hospitals. Service users in MCH institutions are predominantly women and children. They are usually disadvantaged with low socioeconomic status and face significant barriers in engaging with healthcare decisions and getting access to medical services. ${ }^{51} \mathrm{MCH}$ services are focused on a special window of the life cycle (childhood, adolescence and reproduction), and their customers are usually healthy. They are more likely to experience a higher level of stress when things go wrong compared with those in illness conditions. MCH institutions in China are considered part of the public health system. They are obliged to place population health as a priority and work in partnership with various stakeholders. ${ }^{22}$

Nine of the 12 dimensions resemble those identified in other PSC studies. ${ }^{10} 242552$ These are management support, regulations and procedures, staffing, teamwork, non-punitive response to adverse events, openness in communication, risk awareness, continuous learning and self-efficacy. The three additional dimensions identified in this study are patient engagement, defensive medical practices and competing interest between public health and individual care. Patient engagement has recently attracted increasing attention from the international community ${ }^{53-55}$ Defensive medical practices, although not always harmful, have switched the core value to the interest of care providers. Evidence shows that defensive practices often involve excessive and sometimes harmful interventions, exacerbating distrust and poor cooperation between patients and care providers. ${ }^{56-58}$ A profit-driven management culture often favours clinical interventions and disease treatment, leaving public health under-resourced, which will eventually lead to consequences in patient safety. ${ }^{46} 47$

Similar to findings of other studies, ${ }^{43} 5960$ both health workers and patients emphasised the importance of individual competency and tended to endorse a punitive strategy for improving patient safety. This runs in counter with a system strategy, which places a strong emphasis on 'upstream' systemic factors. ${ }^{43}$ Although it is fundamental to address system flaws for achieving sustainable safety outcomes, ${ }^{61}{ }^{62}$ blaming individuals is often emotionally more satisfying. ${ }^{43} 5960$ Knowledge of errors may help individuals thwart some systemic failures. ${ }^{63}$

\section{Challenges for nurturing PSC}

The concept of PSC reflects the philosophy of patient-centred healthcare. In reality, however, the concerns of health workers may not always be aligned with those of the patients. There may exist cognitive conflicts and interest conflicts between health workers and patients. This study involved managers, care providers and patients as participants. We found that patients are more likely to focus on financial security, psychological safety assurance and engagement in decision-making, whereas health workers are more concerned about the organisation of technical services. This may impose serious barriers for health workers to communicate with patients effectively and involve patients in clinical decisions in a meaningful way. Interest conflicts between patients and providers make the situation even worse, fuelling defensive behaviours from both sides. Cognitive and interest conflicts threaten mutual understanding, trust and cooperation between patients and health workers and thereby damage the safety and quality of patient care. ${ }^{64-68}$

Poor PSC can also be shaped by broad policy and social environments. Health workers have to consider the interests of their employers and follow policy and regulatory requirements. Over the past few decades, MCH institutions in China have been exposed to intense market competitions. The low-salary and high-bonus system encourages health workers to increase services, but sometimes at the cost of sacrificing patient interests. The distrust of patients in health services is prevalent. In extreme cases, this has been transformed into medical violence. The legal system and the public media have played a small role, if at all, in the improvement of social environments. ${ }^{69-74}$

\section{Limitations and further studies}

This study was conducted in six MCH institutions, and the results are context specific. Caution needs to be taken in relation to the generalisation of the results. The study provides a high-level classification of patient safety, which 
should not be treated as an operational taxonomy to be used directly in practices.

The PSC framework was developed through a qualitative study. Further studies are needed to quantify the reliability and validity of the instrument. There is also a need to verify the association between PSC and patient care outcomes.

\section{Conclusion}

This study developed a 12-dimensional framework for PSC in MCH institutions in China. Despite general similarities between this instrument and existing instruments measuring PSC in hospitals, there are some features which are specific to $\mathrm{MCH}$ institutions. Three additional dimensions (patient engagement, defensive medical practices and competing interest between public health and individual care) are included. The focus of our instrument is more about 'health' rather than 'diseases'. Adverse events arising from MCH services as well as health consequences as a result of the absence of needed services (eg, preventive care) are considered equally important in relation to patient safety.

Acknowledgements The authors wish to acknowledge the contributions of the National Centre for Women and Children's Health and the six MCH institutions for supporting the field work. We thank all of the interviewers and interviewees and those who offered help with this study.

Contributors YYW and YW conceived and designed the study and oversaw the data collection. CL and WL participated in the design of the study and the development of the interview tools. HS participated in data collection and analyses. YYW led the data analyses and writing of the manuscript. CL guided the development research methodology and interpretation of the findings. As co-corresponding authors, YW and CL contributed equally to this study. All authors contributed to the drafting of the article and read and approved the final version of the manuscript.

Funding This study was funded by Beijing Municipal Education Commission, Beijing Key Disciplines(Maternal, Child and Adolescent Health).

Competing interests None declared.

Ethics approval Peking University Institutional Review Board; Peking University Third Hospital Medical Science Research Ethics Committee.

Provenance and peer review Not commissioned; externally peer reviewed.

Data sharing statement The raw data supporting the conclusions of this article are included in the article as interview excerpts. The full interview transcripts remain the property of the Division of Maternal and Child Health, School of Public Health, Peking University, which are accessible by contacting the corresponding author atwangyan@bjmu.edu.cn.

Open Access This is an Open Access article distributed in accordance with the Creative Commons Attribution Non Commercial (CC BY-NC 4.0) license, which permits others to distribute, remix, adapt, build upon this work non-commercially, and license their derivative works on different terms, provided the original work is properly cited and the use is non-commercial. See: http://creativecommons.org/ licenses/by-nc/4.0/

(c) Article author(s) (or their employer(s) unless otherwise stated in the text of the article) 2017. All rights reserved. No commercial use is permitted unless otherwise expressly granted.

\section{REFERENCES}

1. Weaver SJ, Lubomksi LH, Wilson RF, et al. Promoting a culture of safety as a patient safety strategy: a systematic review. Ann Intern Med 2013;158:369-74.

2. Kristensen $S$, Christensen $K B$, Jaquet $A$, et al. Strengthening leadership as a catalyst for enhanced patient safety culture: a repeated cross-sectional experimental study. BMJ Open 2016;6:e010180.

3. Azami-Aghdash S, Ebadifard Azar F, Rezapour A, et al. Patient safety culture in hospitals of Iran: a systematic review and meta-analysis. Med J Islam Repub Iran 2015;29:251.

4. Azer SA, Baharoon S. Medical error reporting: is it about physicians' knowledge and their practice or patient safety culture in the workplace? East Mediterr Health J. 2016;22:228-9.

5. Verbakel NJ, Langelaan M, Verheij TJ, et al. Effects of patient safety culture interventions on incident reporting in general practice: a cluster randomised trial. Br J Gen Pract 2015;65:e319-e329.

6. Bishop AC, Cregan BR. Patient safety culture: finding meaning in patient experiences. Int J Health Care Qual Assur 2015;28:595-610.

7. McKeown C. Patient safety culture: theory, methods \& application. Ergonomics 2016;59:1132-3.

8. Singer SJ, Vogus TJ. Safety climate research: taking stock and looking forward. BMJ Qual Saf 2013;22:1-4.

9. Halligan M, Zecevic A. Safety culture in healthcare: a review of concepts, dimensions, measures and progress. BMJ Qual Saf 2011;20:338-43.

10. Sexton JB, Helmreich RL, Neilands TB, et al. The Safety Attitudes Questionnaire: psychometric properties, benchmarking data, and emerging research. BMC Health Serv Res 2006;6:44.

11. El-Jardali F, Dimassi $H$, Jamal D, et al. Predictors and outcomes of patient safety culture in hospitals. BMC Health Serv Res 2011;11:45.

12. Singer S, Lin S, Falwell A, et al. Relationship of safety climate and safety performance in hospitals. Health Serv Res 2009;44:399-421.

13. Hill MR, Roberts MJ, Alderson ML, et al. Safety culture and the 5 steps to safer surgery: an intervention study. Br J Anaesth 2015;114:958-62.

14. Xuanyue M, Yanli N, Hao C, et al. Literature review regarding patient safety culture. J Evid Based Med 2013;6:43-9.

15. Sammer CE, Lykens K, Singh KP, et al. What is patient safety culture? A review of the literature. J Nurs Scholarsh 2010;42:156-65

16. Health - United Nations Sustainable Development 2017. http://www. un.org/sustainabledevelopment/health/

17. Guo Y, Bai J, Na H. The history of China's maternal and child health care development. Semin Fetal Neonatal Med 2015;20:309-14.

18. Ren Z, Song P, Theodoratou E, et al. China's human resources for maternal and child health: a national sampling survey. BMC Health Serv Res 2015;15:561.

19. GMM Global, regional, and national levels of maternal mortality, 1990-2015: a systematic analysis for the Global Burden of Disease Study 2015. Lancet 2016;388:1775-812.

20. GBD 2015 Child Mortality Collaborators. Global, regional, national, and selected subnational levels of stillbirths, neonatal, infant, and under-5 mortality, 1980-2015: a systematic analysis for the Global Burden of Disease Study 2015. Lancet 2016;388:1725-74.

21. The number of medical and health institutions in the country by the end of June 2016 - National Health and Family Planning Commission of the people's Republic of China. 2016. http://www.nhfpc.gov.cn/mohwsbwstjxxzx/s7967/201608/ 87343c7d63ce41ca8d8fddf7a5db66b7.shtml

22. Guidance on standardized organizational construction and management of maternal and child health service institutions National Health and Family Planning Commission of the people's Republic of China. 2016. http://www.nhfpc.gov.cn/fys/s3581/ 201512/a0dcaf1f20624769a9a3b2dafa0280ab.shtml

23. Feng XL, Theodoratou E, Liu L, et al. Social, economic, political and health system and program determinants of child mortality reduction in China between 1990 and 2006: a systematic analysis. J Glob Health 2012;2:010405.

24. Wagner C, Smits M, Sorra J, et al. Assessing patient safety culture in hospitals across countries. Int J Qual Health Care 2013;25:213-21.

25. Singer SJ, Gaba DM, Geppert JJ, et al. The culture of safety: results of an organization-wide survey in 15 California hospitals. Qual Saf Health Care 2003;12:112-8.

26. Quillivan RR, Burlison JD, Browne EK, et al. Patient safety culture and the second victim phenomenon: connecting culture to staff distress in nurses. Jt Comm J Qual Patient Saf 2016;42:377-AP2.

27. Hoffmann B, Miessner C, Albay Z, et al. Impact of individual and team features of patient safety climate: a survey in family practices. Ann Fam Med 2013;11:355-62.

28. Nguyen G, Gambashidze N, Ilyas SA, et al. Validation of the safety attitudes questionnaire (short form 2006) in Italian in hospitals in the northeast of Italy. BMC Health Serv Res 2015;15:284.

29. Chen IC, Li HH. Measuring patient safety culture in Taiwan using the Hospital Survey on Patient Safety Culture (HSOPSC). BMC Health Serv Res 2010;10:152.

30. Nie $\mathrm{Y}, \mathrm{Mao} X, \mathrm{Cui} \mathrm{H}$, et al. Hospital survey on patient safety culture in China. BMC Health Serv Res 2013;13:228. 
31. Zhu J, Li L, Zhao H, et al. Development of a patient safety climate survey for Chinese hospitals: cross-national adaptation and psychometric evaluation. BMJ Qual Saf 2014;23:847-56.

32. Zhou P, Bundorf MK, Gu J, et al. Survey on patient safety climate in public hospitals in China. BMC Health Serv Res 2015;15:53.

33. X zw GUO. Revision of Safety attitudes questionnaire and. Chinese Journal of Nursing Education 2010:151-4.

34. Yan X, Dai Z, Hu D. Measuring patient safety culture in women healthcare hospital by using the hospital survey on patient safety culture. Chinese Health Quality Management 2013;20:75-8.

35. Nieva VF, Sorra J. Safety culture assessment: a tool for improving patient safety in healthcare organizations. Qual Saf Health Care 2003;12(Suppl 2):17ii-23.

36. Charmaz K. Constructing grounded theory. 2nd edition. London, 2014.

37. Foley G, Timonen V. Using grounded theory method to capture and analyze health care experiences. Health Serv Res 2015;50:1195-210.

38. Liu C, Liu W, Wang Y, et al. Patient safety culture in China: a case study in an outpatient setting in Beijing. BMJ Qual Saf 2014;23:556-64.

39. Dovey SM, Meyers DS, Phillips RL, et al. A preliminary taxonomy of medical errors in family practice. Qual Saf Health Care 2002;11:233-8.

40. Clayman ML, Makoul G, Harper MM, et al. Development of a shared decision making coding system for analysis of patient-healthcare provider encounters. Patient Educ Couns 2012;88:367-72.

41. Kirilenko AP, Stepchenkova S. Inter-coder agreement in one-to-many classification: fuzzy kappa. PLoS One 2016;11:e0149787.

42. Bottle A, Jarman B, Aylin P. Hospital standardized mortality ratios: sensitivity analyses on the impact of coding. Health Serv Res 2011:46:1741-61.

43. World Health Organization. Patient safety curriculum guide:multi-professional edition. Geneva: World Health Organization, 2011.

44. Duckett J, Hunt $\mathrm{K}$, Munro N, et al. Does distrust in providers affect health-care utilization in China? Health Policy Plan 2016;31:1001-9.

45. Narveson J. Comment on Levy's 'Forced to be free? Increasing patient autonomy by constraining it'. J Med Ethics 2014;40:302-3.

46. McGregor MJ, Cohen M, Stocks-Rankin CR, et al. Complaints in for-profit, non-profit and public nursing homes in two Canadian provinces. Open Med 2011;5:e183-92.

47. Comondore VR, Devereaux PJ, Zhou Q, et al. Quality of care in for-profit and not-for-profit nursing homes: systematic review and meta-analysis. BMJ 2009;339:b2732

48. Klemp K, Dovey S, Valderas JM, et al. Developing a patient safety incident classification system for primary care. A literature review and Delphi-survey by the LINNEAUS collaboration on patient safety in primary care. Eur J Gen Pract 2015;21:35-8.

49. Keriel-Gascou M, Brami J, Chanelière $\mathrm{M}$, et al. [Which definition and taxonomy of incident to use for a French reporting system in primary care settings?]. Rev Epidemio/ Sante Publique 2014;62:41-52.

50. Mikkelsen KL, Thommesen J, Andersen HB. Validating the danish adaptation of the World Health Organization's International Classification for Patient Safety classification of patient safety incident types. Int J Qual Health Care 2013;25:132-40.

51. Sustainable Development Goals (SDGs): World Health Organization. 2017 http://www.who.int/sdg/en/ (updated 2017-04-1102:38:11)

52. Parker D. Managing risk in healthcare: understanding your safety culture using the Manchester Patient Safety Framework (MaPSaF). $J$ Nurs Manag 2009;17:218-22.

53. Davis RE, Jacklin R, Sevdalis N, et al. Patient involvement in patient safety: what factors influence patient participation and engagement? Health Expect 2007;10:259-67.
54. Sahlström M, Partanen P, Rathert C, et al. Patient participation in patient safety still missing: patient safety experts' views. Int J Nurs Pract 2016;22:461-9.

55. Vaismoradi M, Jordan S, Kangasniemi M. Patient participation in patient safety and nursing input - a systematic review. J Clin Nurs 2015;24:627-39.

56. Deng W, Klemetti R, Long Q, et al. Cesarean section in Shanghai: women's or healthcare provider's preferences? BMC Pregnancy Childbirth 2014;14:285.

57. Renkema E, Broekhuis M, Ahaus K. Conditions that influence the impact of malpractice litigation risk on physicians' behavior regarding patient safety. BMC Health Serv Res 2014;14:38

58. Ortashi O, Virdee J, Hassan R, et al. The practice of defensive medicine among hospital doctors in the United Kingdom. BMC Med Ethics 2013;14:42.

59. Reason J. Human error: models and management. BMJ 2000;320:768-70.

60. Reason J. Safety in the operating theatre-part 2: human error and organisational failure. Qual Saf Health Care 2005;14:56-60.

61. Charles R, Hood B, Derosier JM, et al. How to perform a root cause analysis for workup and future prevention of medical errors: a review. Patient Saf Surg 2016;10:20

62. Holdsworth MT, Bond R, Parikh S, et al. Root cause analysis design and its application to pharmacy education. Am J Pharm Educ 2015;79:99.

63. Reason J. Beyond the organisational accident: the need for "erro wisdom" on the frontline. Qual Saf Health Care 2004;13 (Suppl 2):ii28-i33.

64. Van Bogaert P, Peremans L, Diltour N, et al. Staff nurses' perceptions and experiences about structural empowerment: a qualitative phenomenological study. PLoS One 2016;11:e0152654.

65. Oduro-Mensah E, Kwamie A, Antwi E, et al. Care decision making of frontline providers of maternal and newborn health services in the greater Accra region of Ghana. PLoS One 2013;8:e55610.

66. Rose DE, Tisnado DM, Tao ML, et al. Prevalence, predictors, and patient outcomes associated with physician co-management: findings from the Los Angeles Women's Health Study. Health Serv Res 2012;47:1091-116.

67. Lee King PA, Cederbaum JA, Kurzban S, et al. Role of patient treatment beliefs and provider characteristics in establishing patientprovider relationships. Fam Pract 2015;32:224-31.

68. Andoh-Adjei FX, Cornelissen D, Asante FA, et al. Does capitation payment under national health insurance affect subscribers' trust in their primary care provider? a cross-sectional survey of insurance subscribers in Ghana. BMC Health Serv Res 2016;16:437

69. Zhang L, Stone TE, Zhang J. Understanding the rise of Yinao in China: a commentary on the little known phenomenon of healthcare violence. Nurs Health Sci 2017;19.

70. Peng W, Ding G, Tang Q, et al. Continuing violence against medical personnel in China: a flagrant violation of chinese law. Biosci Trends 2016;10:240-3

71. Hui EC. The contemporary healthcare crisis in China and the role of medical professionalism. J Med Philos 2010;35:477-92.

72. Huong DB, Phuong NK, Bales S, et al. Rural health care in Vietnam and China: conflict between market reforms and social need. Int $\mathrm{J}$ Health Serv 2007;37:555-72.

73. Hou J, Michaud C, Li Z, et al. Transformation of the education of health professionals in China: progress and challenges. Lancet 2014;384:819-27.

74. Violence against doctors: Why China? Why now? What next? Lancet 2014;383:1013. 